seldom does a gonorrheal infection require an immediate operation, while infections from abortions frequently require operation in the acute attack.

In all my cases the vaginal fistula closed promptly, but it is only fair to state that a permanent fistula is doubtless to be expected occasionally. Recently I met with such a case, operated by another surgeon, in which a fistula was left. The patient, when she came to $m \theta$, was in such a condition as not to contraindicate abdominal section, which was done and the woman recovered.

Only twice have I removed adnexa by the vaginal route, except when hysterectomy was done at the same time. In one of these cases no trouble was experienced, in the other so many adhesions were met with that I wished most heartily that the abdominal route had been selected. It gave one a thorough appreciation of the truth that the hand directed by the eye is worth much more than one or two fingers groping in the dark. This assertion, of course, labels me as not a skilful operator by the vaginal route, but I have seen a helpless expression on the face of several skilful vaginal sectionists, when I felt positive that one would have had clear sailing had the abdominal route been chosen. In general there can be no question that celiotomy possesses many points of advantage over vaginal section. Not the least of these is that on $\theta$ can see, as well as feel, what is being done. How frequently, in loosening adhesions, do we find the intestines, if not torn, at least so denuded that it is deemed unsafe to leave them without covering with peritoneum by means of Czerny sutures! In doing such work per vaginam we are almost entirely deprived of an opportunity of resorting to this conservative and lifesaving procedure, being often left in doubt as to whether the bowels have been wounded or not. Even when the intestine has not been dangerously injured, it is denuded of peritoneum, and when no opportunity has been given to cover the raw surface, troublesome and painful adhesions are likely to form. Several surgeons are advocating conservative work upon the tubes and ovaries through the vagina. The procedure is to draw the tube and ovary through the vaginal incision, examine, puncture, cauterize, or resect, according to the condition present, and then return the parts to the abdominal cavity. If, as I believe, many of the most painful affections of the pelvis are produced by prolapse of the ovaries, with resulting traumatism by uterus and loaded rectum, this forcible dragging down can not but result in an aggravation of the symptoms, for there is no way of insuring the perfect restoration of such ovaries to their normal position by way of the small and deep opening through the vaginal vault. In chronic inflammations in the pelvis, if there is unquestionably a collection of pus low down, at a point easily accessible from the vagina, the vaginal incizion is doubtless safer and in every case to be preferred. In all chronic inflammations, unless the collection is low down, the abdominal incision is in every way better, safer, and more likely to result in symptomatic as well as anatomic cure. As previously stated, in acute inflammations it seems usually better not to operate, except in the conditions mentioned. The question naturally arises: How long is it best to wait after the acute symptoms have subsided before a celiotomy should be undertaken? It is claimed that an acute infection immunizes a patient for a short period-the exact time not yet very definitely ascertained. Believing this to be the case, the time of election for an operation, if required, would be within a few days after the subsidence of the acute symptoms.

Regarding the technic, the bounds set for this paper will not permit a discussion. One point only $\bar{I}$ feel constrained to mention. If there is any pelvic tissue it is the worst kind of treatment to resort to irrigations and thus carry infectious matter into the uninfected recesses of the abdominal cavity. It is much better to wipe out carefully and then drain, either through the lower angle of the abdominal incision, or, what is better, through the vagina. It is very easy to make an incision through Douglas' pouch and thus get downhill drainage. Rarely, it may be necessary to make use of through-and-through drainage.

\section{THE MEDICAL PROFESSION.}

IS IT GOING INTO VOLUNTARY BANKRUPTCY?

\section{BY LEWIS SCHOOLER, M.D.}

DES MOINES, IOWA.

The plea of an overcrowded profession and low fees, as well as too many medical colleges and free clinics, have each in turn received a great deal of attention, with apparently no results, unless upon the theory of suggestion it has increased the evils that are complained of. This is, no doubt, more perceptible to clinicians than to others; and having conducted a clinic for many years, I may possibly be able to delineate a few occurrences that will prove interesting to the profession at large.

Clinical teaching has been so emphasized by the colleges and by the demands of the profession, that undue importance has been given to that feature in all colleges during the last few years, so much so that the institutions that have advertised the greatest number of clinics have generally obtained the largest classes. That this has been a great gain to the profession in general, the writer emphatically denies, and equally emphatically denies the supposed gain to the students. In acceding to the demands of the profession for strictly clinical teaching, prodigious efforts are put forth in order to obtain the necessary clinical material. The friends of the school are either publicly or privately encouraged, if not absolutely solicited, to act as agents of the school, in order that the material may be abundant. When this is the case it necessarily follows that little or no scrutiny is exercised as to the character of the persons who wish to avail themselves of the advantages of Professor - - 's clinic, and the distinguished professor, being partially intoxicated by reason of his rapidly increasing popularity, and entirely forgetting that a "free show always draws well," continues to operate upon poor and rich alike.

By way of confession, and that I may not seem to have the other fellow constantly in view, to the exclusion of all retrospective researches, I will admit that I have myself, operated upon at least one case who came to the hospital gorgeously bedecked with diamonds worth many hundreds of dollars, besides being clothed in "purple and fine linen," with a sealskin sacque over all. Others may or may not have had a similar experience. That this was a wrong to the profession, I confess. That similar wrongs are being perpetrated daily is not doubted at all by any one familiar with clinical work. The real question at issue is: Who is to blame? For one, I am willing to share a portion of it. There are few, if any, schools 
that derive all their clinical material from the cities iarity with a few of the causes that are likely to imor towns in which they are located. A considerable poverish the profession, if persisted in, let us next portion comes from the country and smaller towns, inquire what is the remedy.

and the patients have been directed to the clinic by In prescribing a remedy, we should not act hastily their family physician, with the information that and without duly considering its effects; in other everything needful will be done without charge. words, we should exercise the same precaution in this Our experience is that there never is a week in the respect that we do in our treatment of disease, viz., year that we are not called upon by persons abun- study well the difficulty that we seek to correct. dantly able to pay for medical and surgical attend- Therefore, after fifteen years of observation and study ance, but who come with either a letter or verbal of this question, I have arrived at some conclusions. message from some practitioner in good standing, which I think are based upon the right principle, and asking that they be allowed the privileges of the clinic.

That their actual financial condition is well known to those who advise them to go before the class can not be doubted, and that this practice of sending such patients to public clinics impoverishes the profession, is equally true. Some have even been known to take long trips to distant cities, stopping at highpriced hotels, having the patient pay their expenses, and in some instances subjecting the patient to a greater outlay of hard cash than would have been the case had they paid for the operation nearer home, instead of going so far in order to get something for nothing.

This is as clearly a wrong toward the profession as anything can be. The money paid to railroads and hotelkeepers is of no benefit whatever to the profession. Why any physician should be interested in obtaining free medical and surgical treatment for those who are able to pay is beyond my comprehension, and had I not so often been made the victim of such practice, I would probably doubt its existence.

That there are too many deceptions of this character goes without saying among those who conduct free clinics. That it is the duty of those connected with the schools to investigate and reject all but the worthy poor, I fully believe. But is there not a duty equally imperative resting upon those who send patients to such places? Are they not equally inter. ested in the welfare of the profession? Does not a wrong done the profession hurt them as well as others? I think the above questions must all be answered affirmatively, and if so, let us pursue the subject a little further.

The wrong done the profession does not end with each individual case. It is too often the introduction of other cases, and the aggregate has a tendency to demoralize the profession, as a business at least. It is also demoralizing to the people. It teaches them to expect gratuitous services, and educates them to the belief that we put no value upon our servicesand if we so educate them, is it any wonder that they patronize quackery? For be it said to the credit of the quack, he exacts a price for all that he does, and it is willingly paid.

Another very taking speech with these people is, that they have a list of schools where they can get work done for nothing, and if your school will not do equally well by them they will move on to the next. In the fierce rivalry between the schools, this may have either consciously or uneonsciously had some effect in inducing some of us to relax where we should have remained firm. The fact probably is, that none of us have been so great sinners in this respect as we are generally supposed to be; but that all of us have been transgressors to a greater extent than is conducive to a high and lofty professional plane, is no doubt true. Having intimated a familsults-not immediately, but in time, the latter being a prime requisite in all reforms.

In the first place, I would not give clinical teaching such a prominent place as it is accorded at the present day, or as it is generally understood to occupy in the schools.

If clinical teaching is the sine qua non of all medical education, why do we prescribe a certain degree of preliminary education before entrance upon the study of medicine? I think that this is necessary and believe that it is. I think that it is equally, yea more, necessary that they have a greater amount of preliminary medical education before arriving at the clinical period of their journey, and when this point is reached it is very important that the student's mind is prepared to recognize what he sees. If he is in this condition, the study of a few carefully selected cases will be more beneficial in properly grounding him in the elementary principles of medical and surgical practice, than a thousand cases merely glanced at. It is not the number of cases seen, but the number studied. If this is not true, then take the young man from the farm, the store or the work-shop, or even from the streets, and set him down in an amphitheater and let him see a thousand or two clinics and then give him a diploma certifying his fitness to hold human lives in his hands. His patrons may then use the old argument in his behalf: "Because he knows nothing else he ought to know something about medicine." If I were to choose between two individuals of equal talents upon entering school and after giving one of them a course entirely clinical, and the other a purely didactic and laboratory course, I would unhestatingly choose the latter, for the reason that he would be well versed in the principles that underlie all rational practice. He would be in a position to be benefited by his observations, when brought into contact with disease, while the other, be he ever so brilliant, would never and could never be more than a case doctor. Just as long as the cases which fall to his care are parallel to the ones he has seen or been impressed by, he would be useful, but in the cases where there was a departure he would fail, and when we recall the fact that departures are the rule, and that typic cases are the exception. it is certainly not hard to predict the outcome in the two cases. True, neither of the above methods is strictly correct; but to which do we most nearly approach in the teachings of our modern medical classes? Evidently the clinical. Therefore, I contend for fewer clinics, better observed and studied, with a greater amount of didactic and laboratory teaching-not more lectures perhaps, but more actual teaching and study. For firmly impressing some things upon the minds of students nothing will ever supersede the lecture. Some things may be well taught by other methods, but in the lecture the stu- 
dent perceives the personality of the lecturer. $\mathrm{He}$ receives from him impressions never to be forgotten, and if he be a lecturer of large practical experience, as he should be, those impressions will prove of the greatest value to the student in after years.

Much has been said of late against the lecture and in favor of the recitation method, but to my mind there is about the same relation existing between them that there is between direct testimony by a witness before a jury and a deposition by some one a thousand miles away. I would, therefore, place less value upon a large clinic, indifferently and hastilyconducted, and more value upon a small and carefullystudied one, one where the student would have abundant time and opportunity for examination, observation and diagnosis; where the lecturer would take more time and exercise more patience in properly aiding the students to arrive at correct conclusions than in a hurried effort to see how many operations he can perform in one afternoon. If this course were pursued, there would be fewer people to introduce as residents of distant States and Territories, and there would be fewer patients with abundant means returning from such places, exhibiting their scars and boasting that they were operated at the clinic of Professor

It is generally supposed that cases of this kind are valuable to both the school and the operator. That the school derives some benefit from them is true, but that the operator gains anything in the end is, I think, quite problematic. But that it is a direct loss to the profession there can be no possible doubt.

The failure to discriminate against persons who would deceive as to their financial condition is one of the professional errors of the day. It is one that is not indulged in by any other of the learned professions; even the clergyman gives the Almighty greater praise when he is serving a wealthy congregation than when his lot is cast with one whose aim is to systematically starve him and his family, and is it any wonder that it is so? While our profession is one that is humane to a fault, and we are, and should be, justly proud of our achievements in that direction, we should not take pride in a benevolence that is conferred upon unworthy objects. This is not only detrimental to the interest of the profession, but of the whole people. Every physician, however limited his practice and field of observation, has seen, time and again, how easily people are degraded and pauperized by misapplied sympathy and so.called philanthropists and charity organizations. Once induced to ascept the fruits of other people's labors without effort and without price, the descent from self-respect and independence to a life of dependence and pauperism is rendered very easy in too many cases. Let us, therefore, insist upon the payment of a price for our services.

The State pays attorneys for defending the vilest criminals; it also pays the cost of appeals to the supreme court, but makes scant provision for medical attendance upon the poor. Not that our lawmakers think more of the criminal than of the unfortunate poor, but they have been taught by us that we will not neglect a sick person because of his poverty. They have, therefore, surrounded the process with such an abundance of red tape, that the individual is too frequently cured or dead before the physician can serure legal sanction for his services. Hence the inc eased amount of uncollectable bills on the books of the general practitioner.
In order to avoid the hideous specter of bankruptcy let the colleges reform their methods of teaching; let the members of the profession have a care in sending people to olinics; let practitioners, general and special, give their patrons to understand that their services are valuable, and we will then have forsaken the paths that are leading us to inevitable, voluntary bankruptey.

\section{SOME PHASES OF INTESTINAL OB- STRUCTION.}

Read before the Mississippi Valley Medical Association, Nashville, Tenn., Oct. 11-16. 1898.

BY A. H. CORDIER, M.D.

Professor of Abdominal Surgery, Kansas City Medical College. KaNsas City. Mo.

Were I asked to name the pathology of the abdom. inal cavity demanding surgery for its relief that was followed by the highest post-operative mortality, I should unhesitatingly say acute intestinal obstruction.

The causes of this condition are so many and varied that to classify them would require a whole volume. Modern methods of diagnosis, in skilled hands, have led to the saving of many cases that a few years ago would have been lost by the delay in resorting to the proper treatment. While the diagnosis of this condition can usually be made early, there are some cases in which the pathologic manifestations are so insidious or vague that their detection requires time and much careful clinical analysis. A very important pathologic fact must be accepted by the practitioner if he would make an accurate diagnosis of the diseases of the abdominal cavity. I refer to the generally accepted view that peritonitis is almost invariably a secondary process. It is important that complications in the progress of a disease should not overshadow the original disease, for the recognition of the cause usually directs the surgery. This is not always true, as long-neglected cases may owe their gravity to later complications. This should be a plea for more painstaking efforts at early diagnosis.

Most cases of acute intestinal obstruction are marked by more or less collapse, the intensity of the shock depending upon the powers of the individual to withstand pain, or upon the extent of the traumatism and the location and completeness of the obstruction, as well as the acuteness of the attack. One individual will possess, in his nervous make-up, a peculiar lack of impressionability to pain, while another will manifest profound collapse and shock from slight nerve injuries.

In arriving at a conclusion from the interpretation of pain, these possible idiosyncrasies should be given proper weight and careful thought. An obstruction in a small intestine will, as a rule, be accompanied by greater shock than a like process in the colon; this is partly explained by the intimate connection of the nerve-supply of the small bowel with the great abdominal ganglia. A large amount of the bowel being constricted implies a greater damage to the sympathetic system; this is true of the small bowel, especially, as its abundant supply of nerves, its thin walls and usual empty condition permit its firmer and more complete compression. An opening just large enough to permit a small bowel to creep in will be much more likely to firmly compress the gut than a larger open. ing through which a colon had found its way.

The very young withstand injuries to the nervous 